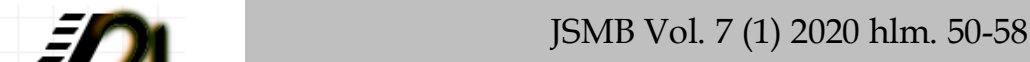 Jurnal Studi Manajemen dan Bisnis \\ http://journal.trunojoyo.ac.id/jsmb
}

\section{Budaya Organisasi Sebagai Mediasi Hubungan Kepemimpinan dan Kinerja Karyawan}

\author{
Endang Setyo Wati, Endi Sarwoko, dan Agung Yuniarianto \\ Magister Manajemen, Program Pascasarjana, Universitas Kanjuruhan Malang
}

Info Artikel

Sejarah Artikel:

Diterima : 7 Juli 2020

Diperbaiki : 23 Juli 2020

Disetujui : 24 Juli 2020

Keywords:

leadership, organizational culture, employee erformance

Kata Kunci:

kepemimpinan, budaya organisasi, kinerja karyawan

DOI:

https://doi.org/10.21107/jsmb.v7i1.7822

Korespondensi:

Nama: Endi Sarwoko

Email:endiswk@unikama.ac.id

\section{Abstract}

The purpose of this study to empirically examine the effect of leadership on employee performance, and examines the mediating role of organizational culture. Using a sample of 90 employees of PT. Ramayana Lestari Sentosa Malang, using the Purposive Sampling method. Data were collected with a questionnaire with a 5-point Likert Scale, analysis techniques using Path Analysis. The result indicates that the leadership have directly affects on employee performance, organizational culture has a mediating role of leadership influence on employee performance. Employee performance can be improved if leadership is able to increase participation, nurture, be democratic and task oriented. Future researchers can examine the role of leadership and culture in building organizational commitment.

\section{Abstraks}

Tujuan penelitian untuk menguji secara empiris pengaruh kepemimpinan terhadap kinerja karyawan, dan menguji peran budaya organisasisebaga mediasi hubungan kepemimpinan dengan kinerja karyawan. Menggunakan sampel sebanyak 90 karyawan PT. Ramayana Lestari Sentosa Malang, dengan metode Purposive Sampling. Data dikumpulkan menggunakan kuesioner dengan Skala Likert 5 poin, teknik analisis menggunakan Path Analysis. Hasil penelitian menunjukkan bahwa kepemimpinan berpengaruh langsung terhadap kinerja karyawan, budaya organisasi memiliki peran mediasi pengaruh kepemimpinan terhadap kinerja karyawan. Peningkatan kinerja karyawan dapat dicapai jika kepemimpinan mampu meningkatkan partisipasi, mengayoni, demokratis dan berorientasi pada tugas. Peneliti selanjutnya dapat menguji peran kepemimpinan dan budaya dalam membangun komitmen organisasi.

ISSN: 2355-9643 (Print)

ISSN: 2460-3775 (on-line)

\section{PENDAHULUAN}

Perkembangan zaman yang semakin pesat mengakibatkan terjadinya persaingan antar perusahaan retail yang tidak dapat dihindari karena semakin banyaknya jumlah perusahaan retail. Tantangan bagi negaranegara berkembang di era globalisasi ini adalah persaingan yang sifatnya terbuka antar pelaku ekonomi global, memaksa peru- 
sahaan dituntut aktif dalam meningkatkan kemampuan serta kualitas sumber daya manusianya. Pengawasan yang dilakukan oleh pimpinan terhadap karyawan disertai dengan komunikasi yang baik dapat menciptakan keakraban yang baik pula. Kepemimpinan adalah perilaku dan strategi sebagai hasil kombinasi dari falsafah, keterampilan, sifat, sikap, yang sering diterapkan seorang pemimpin ketika ia mencoba mempengaruhi kinerja bawahannya (Tampubolon, 2004). Kreitner et al. (2002) menyatakan bahwa pemimpin mendorong kinerja yang lebih tinggi dengan cara memberikan kegiatan-kegiatan yang mempengaruhi bawahannya agar percaya bahwa hasil yang berharga bisa dicapai dengan usaha yang serius.

Salah satu elemen kunci kesuksesan bagi perusahaan adalah kemampuan manajer memotivasi karyawan untuk mencapai potensi mereka, dan menerima perubahan (Kara et al., 2013). Keberhasilan suatu organisasi akan ditentukan bagaimana ke-mampuan pemimpin untuk mengorganir sumberdaya yang dimiliki, termasuk sumber-daya manusia. Kondisi bisnis yang perubahannya sangat dinamis, peran pemimpin sangat penting untuk keberhasilan suatu organisasi. Kepemimpinan adalah kemampuan mempengaruhi orang agar berusaha dengan sukarela mencapai tujuan (Igbaekemen, 2014). Kepemimpinan adalah membahas tentang mengatasi perubahan (Robbins \& Judge, 2015). Gaya kepemimpinan merupakan alat manajemen yang digunakan untuk meningkatkan hubungan positif dengan karyawan, meningkatkan iklim organisasi, dan meningkatkan kinerja (Kozak \& Uca, 2008).

Pemimpin sebuah organisasi memiliki otoritas untuk menentukan bagaimana organisasi akan dijalankan, dan memiliki peran dalam mempengaruhi budaya dalam organisasi (Taormina, 2008), selanjutnya budaya yang kuat dari suatu organisasi akan membantu meningkatkan tingkat kinerja (Awadh \& Alyahya, 2018). Kepemimpinan berperan penting dalam menciptakan suasana dan budaya dalam suatu organisasi (Alghazo \& Al-Anazi, 2016). Kotter \& Heskett (2008) mengatakan bahwa budaya yang kuat dapat menghasilkan efek yang sangat mempengaruhi individu dan kinerja, bahkan dalam suatu lingkungan bersaing pengaruh tersebut dapat lebih besar daripada faktor-faktor lain, seperti struktur organisasi, analisis keuangan, dan lain-lain. Beberapa penelitian tersebut menunjukkan adanya keterkaitan antara kepemimpinan, budaya dan kinerja karyawan.

Penelitian telah membuktikan adanya hubungan antara kepemimpinan dengan kinerja karyawan. Servant leadership dapat meningkatkan kinerja karyawan (Awan et al., 2012), kepemimpinan demokratis dan laissezfaire berpengaruh terhadap kinerja karyawan (Igbaekemen, 2014), gaya kepemimpinan transaksional memiliki pengaruh positif signifikan terhadap kinerja (García-Morales et al., 2012; Obiwuru et al., 2011). Semua penelitian tersebut menjelaskan bahwa berbagai gaya kepemimpinan terbukti mampu meningkatkan kinerja. Namun beberapa penelitian menunjukkan hasil yang berbeda, seperti penelitian Darto et al. (2015) bahwa kepemimpinan transformasional maupun kepuasan kerja tidak mempengaruhi kinerja, Sihombing et al. (2016) yang menemukan bahwa servant leadership tidak berpengaruh terhadap kinerja.

Hal ini menunjukkan masih adanya perdebatan dikalangan peneliti terkait peran masing-masing gaya kepemimpinan terhadap kinerja karyawan. Masih diperlukan penelitian lebih lanjut hubungan antara kepemimpinan dengan kinerja karyawan, dalam hal ini penelitian ini akan dikembangkan dengan menguji keterkaitan kepemimpinan dengan kinerja, dan menguji peran budaya organisasi sebagai mediasi. Tujuan penelitian untuk menganalisis hubungan gaya kepemimpinan dengan kinerja karyawan, dan peran budaya organisasi sebagai mediasi gaya kepemimpinan dengan kinerja.

\section{KAJIAN PUSTAKA}

\section{Kepemimpinan dan Kinerja Karyawan}

Kepemimpinan adalah suatu proses mempengaruhi sekelompok orang untuk bekerja secara bersama untuk mencapai tujuan organisasi (Andang, 2014). Pendapat lain menyatakan kepemimpinan adalah proses mempengaruhi orang untuk mendapatkan hasil yang diinginkan (De Jong \& Den Hartog, 2007). Kepemimpinan adalah upaya mempengaruhi usaha individu dan kelompok untuk mencapai tujuan organisasi (Sutrisno, 2009). Berbagai pengertian kepemimpinan pada prinsipnya adalah kemampuan sese- 
orang untuk mempengaruhi dan mengarahkan seseorang atau sekelompok orang, agar tujuan organisasi tercapai.

Masing-masing pempimpin memiliki strategi dan cara yang berbeda dalam mempengaruhi dan mengarahkan pengikut atau memiliki gaya yang berbeda-beda sesuai dengan karakteristik organisasi dan pengikut, dan berbagai gaya kepemimpinan telah diteliti dalam kontek organisasi maupun karyawan. García-Morales et al. (2012) menyatakan bahwa transformational leadership mempengaruhi kinerja organisasi, melalui pembelajaran dan inovasi. Obiwuru et al. (2011) dalam penelitiannya menemukan bahwa gaya kepemimpinan transaksional memiliki pengaruh positif terhadap kinerja, temuan lainnya dinyatakan bahwa kepemimpinan transaksional lebih tepat dalam mendorong kinerja pada perusahaan skala kecil daripada gaya kepemimpinan transformasional. Didukung penelitian Asrar-ul-Haq \& Kuchinke (2016) kepemimpinan tranformasional berperan terhadap kinerja. Kepemimpinan transformasional akan membantu pengikut untuk mencapai tujuan dan misi organisasi (Tajasom et al., 2015).

Hasil penelitian Syafii et al. (2015) menyatakan bahwa terdapat tiga variabel yang mempengaruhi kinerja karyawan, yaitu gaya kepemimpinan, budaya organisasi, dan motivasi kerja. Basit et al., (2017) menemukan bahwa gaya kepemimpinan demokratis memiliki dampak positif yang signifikan terhadap kinerja karyawan, sedangkan gaya kepemimpinan autokratik pengaruhnya negatif. Lebih lanjut dijelaskan bahwa saat pendekatan demokratis diterapkan, kinerja karyawan akan meningkat. Widodo (2017) dalam penelitiannya menjelaskan bahwa kepemimpinan berpengaruh terhadap kinerja, karena kepemimpinan akan mendorong bawahan untuk bekerja lebih baik.

$\mathrm{H}_{1}$ : Kepemimpinan berpengaruh positif terhadap kinerja karyawan

\section{Budaya Organisasi dan Kinerja Karyawan}

Budaya organisasi didasarkan pada serangkaian nilai, asumsi, keyakinan, dan perilaku, dan bagaimana mereka secara kolektif mempengaruhi perubahan, karyawan, dan kinerja (Carlström \& Ekman, 2012). Penelitian keterkaitan budaya kinerja telah dilakukan para peneliti terdahulu dengan hasil bahwa budaya organisasi berpengaruh signifikan terhadap kinerja. Temuan penelitian menunjukkan bahwa budaya yang kuat dari suatu organisasi akan membantu meningkatkan tingkat kinerja (Awadh \& Alyahya, 2018). Penelitian Weerasinghe (2017) menyimpulkan bahwa budaya organisasi akan memberdayakan kerja tim dan meningkatkan semangat kerja ditempat kerja mereka, untuk mencapai hasil kinerja yang baik. Sejalan dengan temuan tersebut Sihombing et al. (2016) juga berhasil menguji bahwa terdapat pengaruh yang signifikan antara budaya organisasi terhadap kinerja karyawan. Dalam konteks organisasi, Ahmad (2012) menyatakan bahwa dimensi-dimensi budaya organisasi memiliki hubungan positif yang signifikan dengan praktik manajemen kinerja. Lebih lanjut dijelaskan bahwa praktek manajemen kinerja sebagai praktik manajemen sumber daya manusia yang mendasar mendukung pandangan bahwa karyawan dan manajer mendapat manfaat dari pemahaman budaya organisasi sebagai faktor kontekstual. $\mathrm{H}_{2}$ : Budaya organisasi yang kuat akan meningkatkan kinerja karyawan

\section{Kepemimpinan dan Budaya Organisasi}

Al-Ali et al. (2017) menyatakan bahwa change leadership memiliki pengaruh positif dan signifikan terhadap dimensi budaya organisasi pada sektor publik. Selanjutnya Sihombing et al. (2016) menyatakan bahwa servant leadership berpengaruh terhadap penghargaan dan budaya organisasi. Penelitian Paschal \& Nizam (2016) menjelaskan bahwa budaya organisasi memiliki dampak besar pada kinerja karyawan. Hasil penelitian tersebut menjelaskan bahwa budaya tergantung pada kepemimpinan, bagaimana pemimpin membangun dan memelihara budaya dalam sebuah organisasi.

H3: Kepemimpinan berpengaruh positif terhadap kinerja karyawan

\section{METODE PENELITIAN}

Penelitian merupakan metode kualitatif dengan pendekatan Survey, menguji hubungan kausalitas kepemimpinan terhadap kinerja karyawan, yang dimediasi oleh budaya organisasi. Penelitian dilakukan pada karyawan PT. Ramayana Lestari Sentosa, Tbk Malang. Populasi penelitian adalah seluruh karyawan, teknik pengambilan sampel meng- 
gunakan Purposive Sampling dengan kriteria karyawan yang telah bekerja 3 tahun lebih, diperoleh sampel sebanyak 90 sampel.

Teknik pengumpulan data menggunakan kuesioner, yang disusun dengan Skala Likert 5 poin, skor 1 untuk tanggapan ketidaksetujuan dan skor 5 untuk tanggapan kesetujuan. Kuesioner sebelum digunakan dilakukan pengujian validitas dan reliabilitas. Pengukuran variabel:

1. Kepemimpinan

Pengukuran kepemimpinan dalam penelitian ini mengacu penelitian dari Wang \& Rode (2010) yang dimodifikasi dengan menggunakan empat dimensi kepemimpinan yaitu partisipatif, pengasuh, birokratis, dan berorientasi tugas.

2. Budaya organisasi

Pengukuran budaya organisasi menggunakan empat indikator: Involvement (keterlibatan); Consistent (konsistensi); Adaptability; dan Mission.

3. Kinerja karyawan

Pengukuran kinerja karyawan menggunakan lima indikator kualitas, efisiensi, kemampuan, ketepatan waktu, pengetahuan karyawan.

Teknik analisis data dalam penelitian dalam rangka menguji hipotesis adalah analisis jalur (path analysis). Path analysis digunakan untuk menganalisis pola hubungan kausal diantara variabel, untuk menguji pengaruh langsung maupun tidak langsung seperangkat variabel bebas (eksogen) terhadap varabel terikat (endogen), koefisien jalur (path) adalah koefisien regresi standar (standardized coefficient). Analisis ini dibantu dengan bantuan software SPSS V22.

\section{HASIL DAN PEMBAHASAN}

\section{Hasil}

Deskripsi masing-masing variabel penelitian disajikan pada tabel 1. Berdasarkan analisis deskriptif bahwa PT. Ramayana Lestari Sentosa, Tbk Malang telah memiliki kepemimpinan yang kuat, baik dalam hal pemimpin yang partisipatif, pengasuh, birokratis, dan berorientasi tugas. Selanjutnya kepemimpinan partisipatif merupakan ciri paling menonjol dibandingkan dimensi kepemimpinan yang lain.
Tabel 1. Analisis Deskriptif

\begin{tabular}{|c|c|c|}
\hline Dimensi & Mean & Std, Deviation \\
\hline \multicolumn{3}{|l|}{ Kepemimpinan } \\
\hline Partisipatif & 4,1333 & 0,88622 \\
\hline Pengasuh & 4,0500 & 0,86131 \\
\hline Birokratis & 4,0556 & 0,89457 \\
\hline Orientasi & 4,0611 & 0,75635 \\
\hline \multicolumn{3}{|c|}{ Budaya Organisasi } \\
\hline Involveme & 4,0722 & 0,68516 \\
\hline Consistent & 4,4556 & 0,62100 \\
\hline Adaptabili & 4,0889 & 0,59764 \\
\hline Mission & 4,2722 & 0,60504 \\
\hline \multicolumn{3}{|l|}{ Kinerja } \\
\hline Kualitas & 4,1778 & 0,82894 \\
\hline Efisiensi & 4,4556 & 0,63884 \\
\hline $\begin{array}{l}\text { Kemampu } \\
\text { an }\end{array}$ & 4,5222 & 0,69067 \\
\hline Ketepatan & 4,3000 & 0,72592 \\
\hline $\begin{array}{l}\text { Pengetahu } \\
\text { an }\end{array}$ & 4,1111 & 0,81343 \\
\hline
\end{tabular}

Sumber: Data diolah

Budaya organisasi di PT. Ramayana Lestari Sentosa, Tbk Malang selama ini dicirikan adanya keterlibatan anggota organisasi dalam mewujudkan tujuan perusahaan, konsistensi pada tujuan, adaptif terhadap perubahan yang terjadi, dan memiliki misi tercapainya tujuan. Dimensi konsistensi merupakan dimensi budaya organisasi paling menonjol di PT. Ramayana Lestari Sentosa, Tbk Malang.

Kinerja karyawan di PT. Ramayana Lestari Sentosa, Tbk Malang dikategorikan baik, dilihat dari kualitas kerja, efisiensi, kemampuan, ketepatan waktu, dan pengetahuan karyawan. Kemampuan dan efisiensi merupakan indikator kinerja yang paling tinggi di antara indikator yang lain.

\section{Analisis Jalur}

Analisis jalur digunakan untuk menguji hubungan langsung kepemimpinan dengan kinerja, dan hubungan tidak langsung yang dimediasi oleh budaya organisasi. Pengujian terhadap masing-masing hubungan antar variabel dilakukan dengan metode Regression Analysis untuk mencari nilai Standardized Coefficient sebagai nilai koefisien jalur. Analisis Regresi dilakukan untuk me- 
nguji 2 model. Model 1 menguji hubungan kausal kepemimpinan, dan budaya organisasi dengan kinerja, sedangkan model 2 hubungan kausal antara kepemim-pinan dengan budaya organisasi.

Tabel 2. Hasil Analisis Regresi

\begin{tabular}{|c|c|c|c|}
\hline Model & Variabel & $\begin{array}{c}\text { Beta } \\
\text { (Standardized } \\
\text { Coefficient) }\end{array}$ & Sig. \\
\hline \multirow[t]{2}{*}{$\begin{array}{l}\text { Model } \\
1\end{array}$} & $\begin{array}{l}\text { Kepemimpi } \\
\text { nan }\end{array}$ & 0,309 & 0,008 \\
\hline & $\begin{array}{l}\text { Budaya } \\
\text { Organisasi }\end{array}$ & 0,328 & 0,005 \\
\hline $\begin{array}{l}\text { Model } \\
2\end{array}$ & $\begin{array}{l}\text { Kepemim } \\
\text { pinan }\end{array}$ & 0,639 & 0,000 \\
\hline
\end{tabular}

Sumber: Data diolah.

Analisis Regresi untuk Model 1, diperoleh hasil kepemimpinan memiliki koefisien jalur positif sebesar 0,309 terhadap kinerja dengan nilai signifikan 0,008 lebih kecil 0,05, artinya kepemimpinan memiliki pengaruh positif signifikan terhadap kinerja karyawan. Hipotesis 1 yang menyatakan kepemimpinan berpengaruh positif terhadap kinerja karyawan diterima.

Hasil analisis, budaya organisasi memiliki koefisien jalur positif sebesar 0,328 terhadap kinerja dengan nilai signifikan 0,005 lebih kecil 0,05, artinya budaya organisasi memiliki pengaruh positif signifikan terhadap kinerja karyawan. Jadi hipotesis 2 yang menyatakan budaya organisasi yang kuat akan meningkatkan kinerja karyawan diterima.

Hasil analisis regresi Model 2, kepemimpinan memiliki koefisien jalur positif sebesar 0,639 terhadap budaya organisasi dengan nilai signifikan 0,000 lebih kecil 0,05, artinya kepemimpinan memiliki pengaruh positif signifikan terhadap budaya organisasi. Hipotesis 3 yang menyatakan kepemimpinan berpengaruh positif terhadap kinerja karyawan diterima.

Berdasarkan hasil analisis Regresi Linier terhadap masing-masing jalur hubungan kausal antar variabel, maka bisa digambarkan model jalur pada gambar 1 .

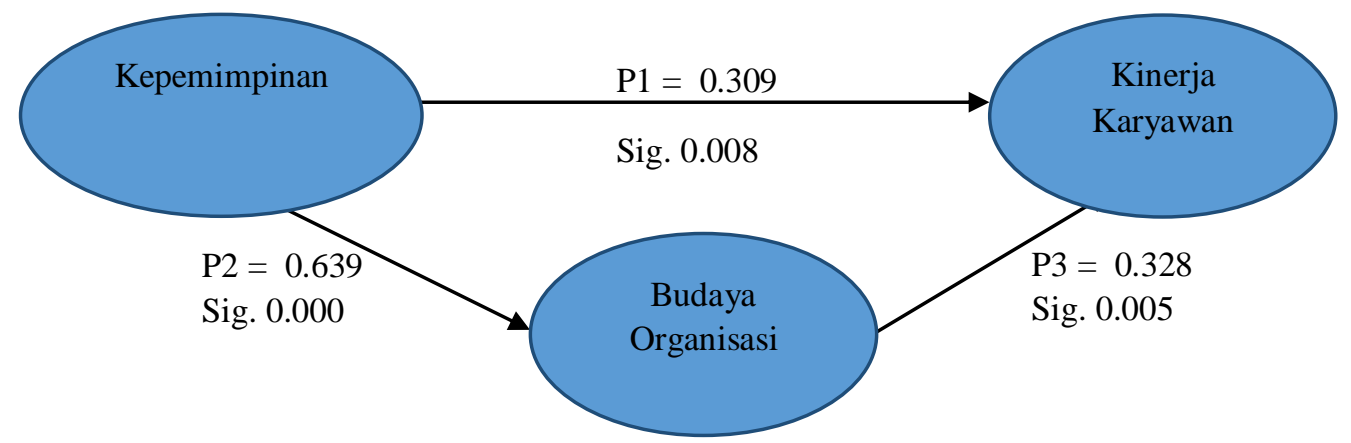

Gambar 1. Model Analisis Jalur

Masing-masing hubungan kausal antar variabel (gambar 1) menunjukkan koefisien jalur positif dan signifikan, kepemimpinan berpengaruh langsung terhadap kinerja karyawan. Selain itu, kepemimpinan berpengaruh tidak langsung ke kinerja karyawan, melalui budaya organisasi. Hubungan kausal langsung (indirect effect) kepemimpinan terhadap kinerja adalah sebesar 0,309 sedangkan hubungan kausal tidak langsung (indirect effect) kepemimpinan terhadap kinerja dimediasi budaya organisasi sebesar $0,639 \times 0,328$ $=0,210$, selanjutnya pengaruh total (total effect) adalah 0,519.

Seluruh hubungan kausal dalam model terbukti memiliki hubungan yang signifikan artinya budaya organisasi berperan sebagai mediasi parsial (partial mediation) dari hubungan antara kepemimpinan dengan kinerja karyawan.

\section{Pembahasan}

\section{Pengaruh kepemimpinan terhadap kinerja}

Temuan dari penelitian menunjukkan bahwa kepemimpinan berpengaruh positif dan signifikan terhadap kinerja karyawan, artinya, semakin tinggi kemampuan yang dimiliki pemimpin akan berpengaruh terhadap peningkatan kinerja karyawan. Kemampuan pemimpin tersebut tercermin dari kemampuan pemimpin untuk berpartisipatif aktif maupun menumbuhkan partisipasi pengikut dalam rangka mencapai tujuan organisasi, kemampuan untuk mengayomi pengikut 
yang memiliki motif dan karakter yang berbeda-beda, tetap memegang birokrasi terkait dengan standar prosedur yang ditetapkan, dan terakhir adalah pemimpin yang berorientasi tugas untuk mewujudkan tujuan organisasi.

Kepemimpinan yang kuat mampu meningkatkan kinerja karyawan, karena pemimpin adalah seseorang yang memiliki peran kunci untuk mengarahkan pengikut dalam menjalankan tugas dalam rangka mencapai tujuan organisasi. Sebagaimana menurut Andang (2014) dan De Jong \& Den Hartog (2007), bahwa kepemimpinan adalah proses mempengaruhi sekelompok orang untuk bekerja secara bersama dalam mencapai tujuan organisasi. Keberhasilan pengikut mencapai kinerja yang diharapkan akan tergantung pada kemampuan pemimpin untuk mempengaruhi dan mengarahkan aktivitas pengikut, mendelegasikan pekerjaan kepada pengikut yang memang memiliki kompetensi di bidang pekerjaan. Kompetensi bukanlah satu-satunya hal yang mempengaruhi kinerja seseorang, jika pimpinan tidak mampu menggali potensi dan memanfaatkan potensi secara tepat tidak akan dicapai kinerja yang diharapkan.

Temuan penelitian ini mendukung penelitian García-Morales et al. (2012) bahwa kepemimpinan transformational mempengaruhi kinerja organisasi, serta penelitian Obiwuru et al. (2011) bahwa gaya kepemimpinan transaksional berpengaruh positif terhadap kinerja. Sejalan pula dari penelitian Asrar-ul-Haq \& Kuchinke (2016) bahwa kepemimpinan tranformasional berperan terhadap kinerja, kepemimpinan transformasional akan membantu pengikut untuk mencapai tujuan dan misi organisasi (Tajasom et al., 2015). Gaya kepemimpinan demokratis memiliki dampak positif yang signifikan terhadap kinerja karyawan, sedangkan gaya kepemimpinan autokratik pengaruhnya negatif (Basit et al., 2017). Kepemimpinan akan berpengaruh terhadap kinerja karyawan, karena kepemimpinan akan mendorong bawahan untuk bekerja lebih baik (Widodo, 2017).

\section{Pengaruh budaya organisasi terhadap kinerja karyawan}

Peran pemimpin dalam organisasi selain mengarahkan perilaku pengikut untuk mencapai tujuan organisasi, pemimpin harus mampu membangun nilai-nilai yang disepakati bersama oleh seluruh anggota organisasi (budaya), sebagai pegangan untuk mewujudkan tujuan organisasi. Temuan penelitian menjelaskan bahwa budaya organisasi berpengaruh positif dan signifikan terhadap kinerja karyawan, jadi semakin kuat budaya organisasi mampu meningkatkan kinerja karyawan.

Budaya organisasi yang kuat mampu meningkatkan kinerja karyawan disebabkan aktivitas budaya akan memberdayakan kerja tim dan meningkatkan semangat kerja ditempat kerja, untuk mencapai hasil kinerja yang baik (Weerasinghe, 2017). Kotter \& Heskett (2008) mengatakan bahwa budaya yang kuat dapat menghasilkan efek yang sangat mempengaruhi individu dan kinerja. Efek dari budaya maka secara kolektif akan menyebabkan terjadinya perubahan di lingkungan organisasi, dan tercapainya kinerja (Carlström \& Ekman, 2012).

Implikasi praktis penelitian terkait budaya organisasi dalam rangka meningkatkan kinerja karyawan, maka organisasi atau pimpinan harus mampu membangun dan mengembangkan dimensi budaya seperti keterlibatan (involvement) untuk menjamin seluruh anggota organisasi merasa terlibat terhadap pencapaian tujuan organisasi. Organisasi harus konsisten untuk mencapai tujuan dengan tetap memiliki kemampuan adaptasi terhadap perubahan pada hal baru. Terakhir, budaya harus mampu menterjemahkan misi organisasi kepada kehidupan sehari-hari di perusahaan.

\section{Pengaruh Kepemimpinan terhadap budaya organisasi}

Hasil analisis menunjukkan bahwa kepemimpinan berpengaruh positif terhadap budaya organisasi, jadi kepemimpinan mampu membangun dan memperkuat budaya organisasi yang di PT Ramayana cabang Malang. Hal ini mendukung pendapat Syafii et al. (2015) yang menyatakan bahwa terdapat tiga variabel yang mempengaruhi kinerja karyawan, yaitu gaya kepemimpinan, budaya organisasi, dan motivasi kerja. Hasil penelitian tersebut menjelaskan bahwa budaya tergantung pada kepemimpinan, bagaimana pemimpin membangun dan memelihara budaya dalam sebuah organisasi. Se- 
bagaimana menurut Paschal \& Nizam (2016) bahwa budaya organisasi memiliki dampak besar pada kinerja karyawan, didukung pula penelitian Al-Ali et al. (2017) dengan temuan bahwa change leadership berpengaruh positif terhadap dimensi budaya organisasi pada sektor publik, serta penelitian Sihombing et al. (2016) yang menemukan bahwa servant leadership berpengaruh terhadap penghargaan dan budaya organisasi.

Implikasi praktis penelitian terkait kepemimpinan dan budaya organisasi, maka pemimpin harus terus membangun nilai-nilai partisipatif bahwa tujuan organisasi adalah bagian dari tujuan semua anggota organisasi, mengayomi kepentingan pengikut, kerja berdasarkan standar, dan selalu berorientasi pada pencapaian hasil dari tugas yang dibebankan. Jika semuanya jika dijalankan secara terus menerus dan konsisten akan menjadi nilai-nilai yang dianut semua anggota organisasi atau menjadi budaya di PT. Ramayana cabang Malang.

Temuan lain dari penelitian ini adalah bahwa kepemimpinan sebagai faktor yang mempengaruhi kinerja, memiliki dampak langsung maupun tidak langsung. Kekuatan kepemimpinan secara langsung berdampak pada peningkatan kinerja, selain itu efektivitas kepemimpinan juga akan berdampak pada penguatan budaya organisasi yang ada di PT. Ramayana Cabang malang, kekuatan budaya juga akan berdampak pada tercapainya peningkatan kinerja karyawan.

\section{SIMPULAN}

Kepemimpinan mampu meningkatkan kinerja karyawan baik secara langsung maupun tidak langsung, yaitu melalui peningkatan budaya organisasi dan selanjutnya berdampak pada peningkatan kinerja. Pemimpin yang memiliki kemampuan partisipatif, mengayomi, birokratif dan ber-orientasi pada tugas mampu mempengaruhi dan mengarahkan karyawan untuk menjalankan tugas dengan baik, sehingga tercapai kinerja yang diharapkan. Kemampuan parti-sipatif juga mampu mendorong keterlibatan (involvement) dari para karyawan, sanggup beradaptasi terhadap perubahan lingkungan, bekerja selalu sesuai standar operasional prosedur yang ada sebagai bagian dari budaya organisasi.
Penelitian ini hanya dilakukan pada satu lokasi perusahaan yaitu Cabang Malang, sehingga memiliki keterbatasan tingkat generalisasi yang rendah, apalagi terkait dengan budaya organisasi, disarankan kepada peneliti berikutnya, untuk mengembangkan pada penelitian yang lebih luas. Peneliti berikutnya juga bisa mengembangkan penelitian terkait kepemimpinan dan budaya dikaitkan dengan komitmen organisasi.

\section{DAFTAR PUSTAKA}

Ahmad, M. S. (2012). Impact of Organizational Culture on Performance Management Practices in Pakistan. Business Intelligence Journal, 5(1), 50-55.

Al-Ali, A. A., Singh, S. K., Al-Nahyan, M., \& Sohal, A. S. (2017). Change management through leadership: the mediating role of organizational culture. International Journal of Organizational Analysis, 25(4), 723-739. https://doi.org/10.1108/IJOA01-2017-1117

Andang. (2014). Manajemen Dan Kepemimpinan Kepala Sekolah: Konsep, Strategi, Dan Inovasi Menuju Sekolah Efektif. Ar-Ruzz Media.

Asrar-ul-Haq, M., \& Kuchinke, K. P. (2016). Impact of leadership styles on employees' attitude towards their leader and performance: Empirical evidence from Pakistani banks. Future Business Journal, 2(1), 54-64. https://doi.org/10.1016/j.fbj.2016.05.00 2

Awadh, A. M., \& Alyahya, M. S. (2018). Impact of organizational culture on employee performance. Prabandhan: Indian Journal of Management, 11(6), 5363.

https://doi.org/10.17010/pijom/2018/ v11i6/128442

Awan, K. Z., Qureshi, I. E. W., \& Arif, S. (2012). The effective leadership style in NGOS: Impact of servant leadership style on employees' work performance and mediation effect of work motivation. International Journal of Economics and Management Sciences, 1(11), 43-56.

Basit, A., Sebastian, V., \& Hassan, Z. (2017). Impact of Leadership style on Employee Performance (a case study on a private organization in Malaysia). International 
Journal of Accounting $\mathcal{E}$ Business Management, 5(2), 112-130.

Carlström, E. D., \& Ekman, I. (2012). Organisational culture and change: implementing person-centred care. Journal of Health Organization and Management, 26(2), 175-191. https://doi.org/10.1108/1477726121123 0763

Darto, M., Setyadi, D., Riadi, S. S., \& Hariyadi, S. (2015). The effect of transformational leadership, religiosity, job satisfaction, and organizational culture on organizational citizenship behavior and employee performance in the regional offices of national institute of public administration, Republic of Indone. European Journal of Business and Management, 7(23), 205-219.

De Jong, J. P. J., \& Den Hartog, D. N. (2007). How leaders influence employees' innovative behaviour. European Journal of Innovation Management.

García-Morales, V. J., Jiménez-Barrionuevo, M. M., \& Gutiérrez-Gutiérrez, L. (2012). Transformational leadership influence on organizational performance through organizational learning and innovation. Journal of Business Research, 65(7), 1040 1050.

Igbaekemen, G. O. (2014). Impact of leadership style on organisation performance: A strategic literature review. Public Policy and Administration Research, 4(9), 126-135.

Kara, D., Uysal, M., Sirgy, M. J., \& Lee, G. (2013). The effects of leadership style on employee well-being in hospitality. International Journal of Hospitality Management, 34(1), 9-18. https://doi.org/10.1016/j.ijhm.2013.02. 001

Kotter, J. P., \& Heskett, J. L. (2008). Corporate culture and performance. Simon and Schuster.

Kozak, M. A., \& Uca, S. (2008). Effective factors in the constitution of leadership styles: A study of Turkish hotel managers. Anatolia, 19(1), 117-134.

Kreitner, R., Kinicki, A., \& Buelens, M. (2002). Organizational behaviour. McGraw Hill London, UK.

Obiwuru, T. C., Okwu, A. T., Akpa, V. O., \& Nwankwere, I. A. (2011). Effects of leadership style on organizational performance: A survey of selected small scale enterprises in Ikosi-Ketu council development area of Lagos State, Nigeria. Australian Journal of Business and Management Research, 1(7), 100.

Paschal, A. O., \& Nizam, D. I. (2016). Effects of Organisational Culture on Employees Performance: International Journal of Accounting and Business Management, 4(1), 19-26. https://doi.org/10.24924/ijabm/2016.0 4/v4.iss1/19.26

Robbins, S. P., \& Judge, T. A. (2015). Perilaku organisasi. Salemba Empat.

Sihombing, S., Astuti, E. S., Mussadieq, M., Hamied, D., \& Rahardjo, K. (2016). The Effect of Servant Leadership to Rewards, Organizational Culture, and its Implication to Employee's Performance (Case Study on the Employees of PT. Bank Tabungan Negara (Persero) Tbk. Indonesia). International Journal of Law and Management, 78(5), 781-796. https://doi.org/10.1108/IJEBR-03-2018428

Sutrisno, E. (2009). Manajemen Sumber Daya Manusia Edisi pertama. Jakarta: Kencana Prenada Media Group.

Syafii, L. I., Thoyib, A., Nimran, U., \& Djumahir. (2015). The Role of Corporate Culture and Employee Motivation as a Mediating Variable of Leadership Style Related with the Employee Performance (Studies in Perum Perhutani). Procedia Social and Behavioral Sciences, 211, 11421147.

https://doi.org/10.1016/j.sbspro.2015.1 1.152

Tajasom, A., Hung, D. K. M., Nikbin, D., \& Hyun, S. S. (2015). The role of transformational leadership in innovation performance of Malaysian SMEs. Asian Journal of Technology Innovation, 23(2), 172-188.

Tampubolon, M. P. (2004). Manajemen Operasional (Operational Management). Ghalia Indonesia.

Taormina, R. J. (2008). Interrelating leadership behaviors, organizational socialization, and organizational culture. Leadership and Organization Development Journal, 29(1), 85-102. 
https://doi.org/10.1108/0143773081084 5315

Wang, P., \& Rode, J. C. (2010). Transformational leadership and follower creativity: The moderating effects of identification with leader and organizational climate. Human Relations, 63(8), 1105-1128.

Weerasinghe, G. (2017). Organization culture impacts on employee motivation: A case study on an apparel company in Sri Lanka. International Journal of Multidisciplinary Research and Development, 4(4), 59-62.

Widodo, D. S. (2017). Pengaruh Budaya Organisasi, Kepemimpinan Dan Kompensasi Melalui Motivasi Kerja Terhadap Kinerja Pegawai. Jurnal Manajemen Motivasi, 13(2), 896-908. 